\title{
Eosinophilia as trigger factor for deep vein thrombosis and pulmonary embolia in a pacient with thrombophilia
}

\author{
Marilena Constantin, Gabriel Zamfirescu, Cristina Voinea, Sorin Constantinescu \\ "Victor Babes" Foundation, Bucharest, Romania
}

\begin{abstract}
Introduction. Pulmonary infiltrate and eosinophilia represent a heterogenous group of diseases causes by extrinsic or intrinsic factors. Extrinsic factors represented by medication or infectious agents (parasites, fungi, mycobacteria) may trigger an eosinophilic immune response. We report the case of a 53 years old male patient with pulmonary infiltrate and eosinophilia secondary to Toxocariasis infection who was diagnosed with deep vein thrombosis and pulmonary embolism one month later from the diagnosis of pneumonia. Further investigations demonstrated a hypercoagulable state.

Case presentation. On March 2015 a 53 years old male came to my office because of a very intense pain on the left posterior thorax which increased by deeply breathing. Physical exam was in normal range, but chest computer tomography without contrast done in emergency showed pulmonary infiltrate at the base of the left lung with pleuritic reaction. Blood tests showed white blood cells at the upper range with eosinophilia $(21.75 \%, 2,050 / \mathrm{mc})$ and inflammatory syndrome. Investigations for eosinophilia showed a positive Western blot test for Toxocara canis so the patient began the treatment with Albendazolum $800 \mathrm{mg} / \mathrm{day}$ for three weeks with positive response. One month later the patient visited us for a pain on the right calf. The ultrasound Doppler vein confirmed the diagnosis of deep vein thrombosis and the chest Computer Tomography with contrast substance described mild right pulmonary embolism. The patient started the anticoagulant treatment. Thrombophilia tests were done, MTHFR A1298C gene and PAI1 675 were positive.

Discussions. Helminthic infections are associated with eosinophilia. Helminths who migrate to the viscera as like as Toxocara canis could produce high eosinophilic response. Our questions was if eosinophilia was responsible for the patient thrombosis or was it only the trigger factor? As two genetic tests for thrombophilia (MTHFR A1298C gene and PAI1 675) were positive we considered deep vein thrombosis and pulmonary embolism in the context of hypercoagulable states.

Conclusion. This case highlights the implication of eosinophilia as trigger factor for vein thrombosis and pulmonary embolism.
\end{abstract}

Keywords: eosinophilia, vein thrombosis, Toxocara canis infection

\section{INTRODUCTION}

Pulmonary infiltrate and eosinophilia represent a heterogeneous group of diseases.

Helminthic infection could produce high eosinophilic response especially in case of helminths who migrate to viscera. It is also known that hypereosinophilia is associated with risk of thrombosis.

We reported the case of a patient with pulmonary infiltrate and eosinophilia secondary to Toxocara infection to whom diagnosis of deep vein thrombosis and pulmonary embolism during the course of disease revealed a hypercoagulable status.

\section{CASE PRESENTATION}

On March 2015 a 53 years old male came to my office for very intense pain on the left posterior thorax which increased by deeply breathing in.

Physical exam described normal weight patient with normal pulmonary exam, without fever, $\mathrm{BP}=$ 120/70 $\mathrm{mmHg}, \mathrm{HR}=75 / \mathrm{min}$. 
Blood tests showed leucocytes at the upper range with hyper eosinophilia $(21.7 \% ; 2,050 / \mathrm{mc})$ and inflammatory syndrome (ESR $16 \mathrm{~mm} / \mathrm{h}$; CRP $5.24 \mathrm{mg} / \mathrm{dl}$; fib $536 \mathrm{mg} / \mathrm{dl})$.

Chest computer tomography without contrast which was done in emergency showed pulmonary infiltrate at the base of the left lung with pleuritic reaction.

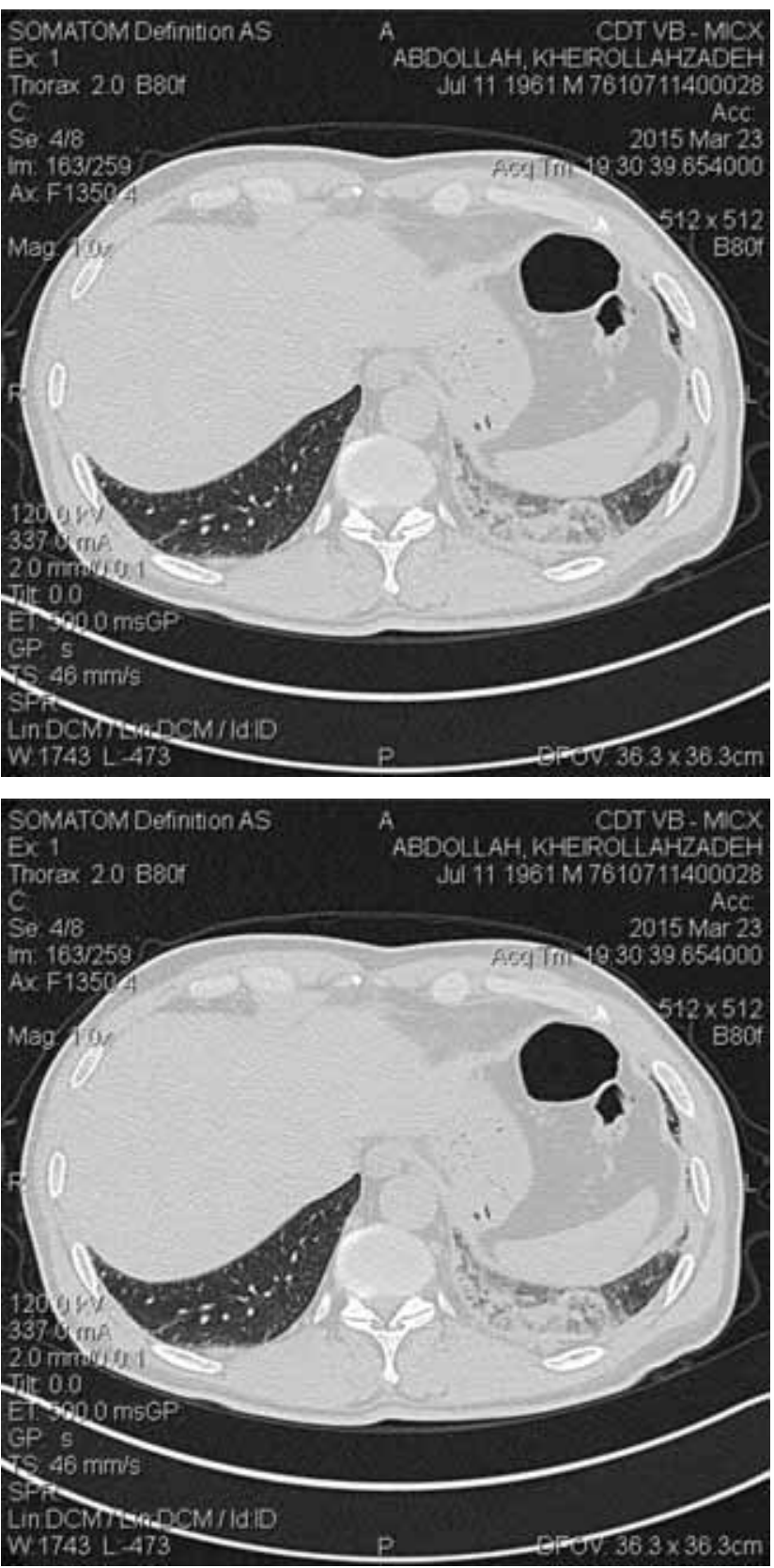

FIGURE 1. Left pulmonary infiltrate

Bronchoscopy with lavage was recommended but the patient refused.

We started the treatment with antibiotic (quinolone) and investigated eosinophilia.

Western Blot Test for Toxocara canis was positive so we began the antiparasitic treatment with
Albendazolum $800 \mathrm{mg} /$ day for three weeks. The eye exam which was done on April 2015 was in normal range.

On April 2015 patient came to my office for pain on the right calf. D-dimers test was high positive and ultrasound Doppler for the right lower limb described deep vein thrombosis.

The patient was hospitalized and the Chest Computer Tomography with contrast substance described mild right pulmonary embolism so it was started the anticoagulant treatment.
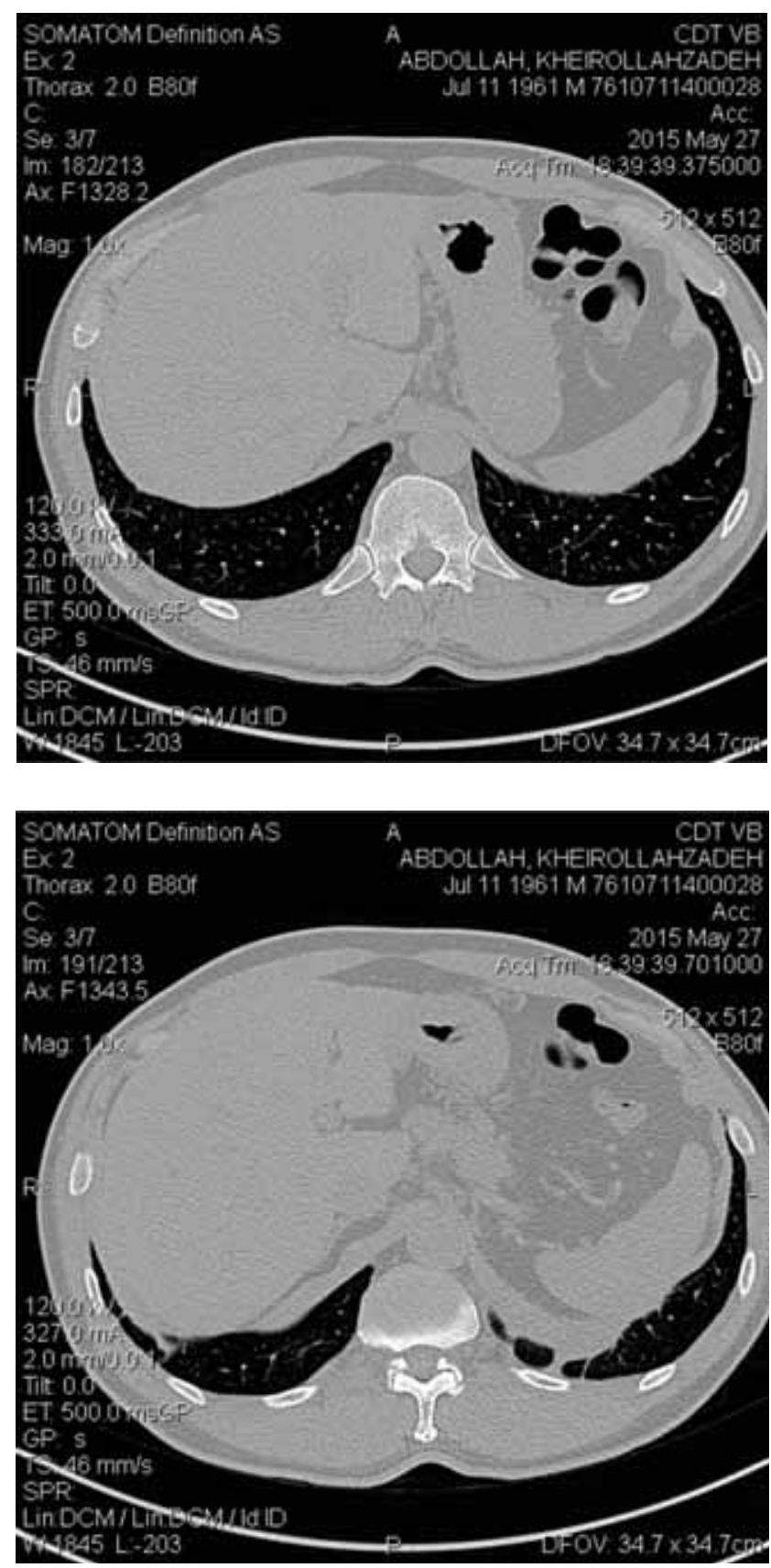

FIGURE 2. Resolution of pulmonary infiltrate

Repeated Chest Computer Tomography with contrast substance on May 2015 showed the resolu- 
tion of pulmonary embolism, no pulmonary infiltrate, only lesions of fibrosis in the left lung.

Ultrasound Doppler for vein thrombosis was almost the same.

Haematologic examination and tests for thrombophilia were done. They were positive to MTHFR A1298C gene and PAI1 675

\section{DIAGNOSIS}

\section{Toxocariasis}

\section{Pulmonary embolia}

\section{Deep vein thrombosis}

\section{Trombophilia}

TABLE 1. Case history

\begin{tabular}{|c|c|}
\hline DATE & BLOOD TEST \\
\hline $24^{\text {th }}$ March & $\begin{array}{l}\mathrm{Hb}=15.8 \mathrm{~g} / \mathrm{dl} ; \mathrm{Ht}=46.6 \% ; \mathrm{L}=9,460 / \mathrm{mm}^{3}, \\
\text { eo }=21.7 \%(2,050 / \mathrm{mcl}) ; \mathrm{T}=232,000 / \mathrm{mm}^{3} ; \\
\mathrm{VSH}=16 \mathrm{~mm} / \mathrm{h} ; \text { fib }=536 \mathrm{mg} / \mathrm{dl} ; \mathrm{CRP}=5.24 \mathrm{mg} / \mathrm{dl} \\
\text { Chest CT: le posterobasal infiltrate with } \\
\text { pahipleuri c reac on; le scizuri s }\end{array}$ \\
\hline $03^{\text {rd }}$ April & $\begin{array}{l}\text { Spirometry: normal; } \\
\text { IgE > } 500 \text { ui/ml; WB Toxocara canis posi ve; } \\
\text { WB Fasciola hepa ca nega ve }\end{array}$ \\
\hline $05^{\text {th }}$ April & $\begin{array}{l}\text { Ecocardiography: normal } \\
\text { An Toxoplasma IgM nega ve; } \\
\text { an Toxoplasma IgG posi ve } \\
\end{array}$ \\
\hline $06^{\text {th }}$ April & $\begin{array}{l}\mathrm{Hb}=15.6 \mathrm{~g} / \mathrm{dl} ; \mathrm{Ht}=45.6 \% ; \mathrm{L}=8,400 / \mathrm{mm}^{3} ; \\
\mathrm{Eo}=19 \%\left(1,600 / \mathrm{mm}^{3}\right) ; \\
\mathrm{T}=253,000 / \mathrm{mm}^{3} ; \mathrm{CRP}=0.8 \mathrm{mg} / \mathrm{dl} ; \mathrm{HIV} \text { nega ve; } \\
\text { an Aspergillus nega ve } \\
\text { urea, crea nine normal }\end{array}$ \\
\hline $21^{\text {st }}$ April & $\begin{array}{l}\text { Pneumology exam: Le pneumonia with } \\
\text { eosinophilia. Toxocariasis. } \\
\text { Recommenda on: bronchoscopia with lavage }\end{array}$ \\
\hline $29^{\text {th }}$ April & $\begin{array}{l}\text { D-dimer test }=4,778 \mathrm{ng} / \mathrm{ml} \text { posi ve } \\
\text { Hospitalized: Pulmonary embolism. Deep right } \\
\text { vein thrombosis. Varicose veins lower limbs. } \\
\text { Toxocariasis. Chronic gastri s } \\
\text { Chest CT with contrast: right mild pulmonary } \\
\text { embolism. } \\
\text { Recommenda on: an coagulant treatment }\end{array}$ \\
\hline $08^{\text {th }}$ May & $\begin{array}{l}\mathrm{L}=6,750 / \mathrm{mm}^{3} ; \text { eo }=6,1 \%(416 / \mathrm{mcl}) ; \\
\mathrm{Hb}=14.5 \mathrm{~g} / \mathrm{dl} ; \mathrm{Ht}=42 \% ; \mathrm{T}=284,000 / \mathrm{mm}^{3} ; \\
\text { D-dimer test }=1,117 \mathrm{ng} / \mathrm{ml} .\end{array}$ \\
\hline $12^{\text {th }}$ May & $\begin{array}{l}\text { Fct. V Leiden nega ve; fct II G } 20210 \text { A nega ve; } \\
\text { MTHFR A1298C gene positive homozigot and } \\
\text { PAl1 } 675 \text { gene positive homozigot }\end{array}$ \\
\hline $21^{\text {st }}$ May & D-dimer test $342 \mathrm{ng} / \mathrm{ml}$ \\
\hline $26^{\text {th }}$ May & $\begin{array}{l}\text { Doppler ultrasound: Right femuropoplitee deep } \\
\text { vein thromboses }\end{array}$ \\
\hline $27^{\text {th }}$ May & $\begin{array}{l}\text { Resolusion of pulmonary embolism; le } \\
\text { posterobasal fibro c changes }\end{array}$ \\
\hline
\end{tabular}

\section{DISCUSSIONS}

Pulmonary infiltrates associated with eosinophilia are described in literature in a heterogenous group of deseases causing by extrinsic and intrinsic factors (see below)

Causes of pulmonary infiltrate with eosinophilia (1):

Idiopathic:

- Loffler syndrome

- pulmonary eosinophilia (acute, chronic)

- idiopathic hypereosinophilic syndrome

Secondary:

- drugs (iodides, aspirin, sulphonamids, nitrofurantoin, penicillins, cephalosporins)

- infections (fungal, parasitic infections: schistosomiasis $50 \%$, ascaris, Toxocara canis)

- allergic bronchopulmonary aspergillosis

- collagen vascular diseases

- malignancies

- eosinophilic vasculitis

- Churg-Strauss syndrome

Searching literature we found a a lot of hypotheses (3) proposed to explain the relationship eosinophilia-thrombosis. First eosinophils release specific eosinophilic factors: major basic protein (MBP) which affects the lipid membrane belayer, increases membrane permeability, induces endothelial damage; eosinophil peroxidase (EPO) which has a cytotoxic effect; eosinophil cationic protein $(\mathrm{ECP})$ which induces endothelial damage; platelet activated factors which induce platelet activation. Second they store and express tissue factors. Third they express CD40 ligand which is involved in initiation and progression of thrombosis.

Eosinophilia that is associated with helminth infection could raise dramatically in some cases regarding to the host response. Generally helminths who migrate to the viscera induce high eosinophilic response.

In our case eosinophilia was induced by infection with Toxocara canis. We don't know exactly how did our patient contact this infection but even if he lives in urban area he goes to the country from time to time.

The global prevalence of infection with Toxocara canis in human is unknown but could rise to $40 \%$ or even more in some countries (CDC). It is higher in rural community. Toxocara canis infects dogs. In the small intestine ingested eggs hatch to the larvae which migrate to the liver, lung, trachea. Clinical manifestation of visceral larva migrans in- 


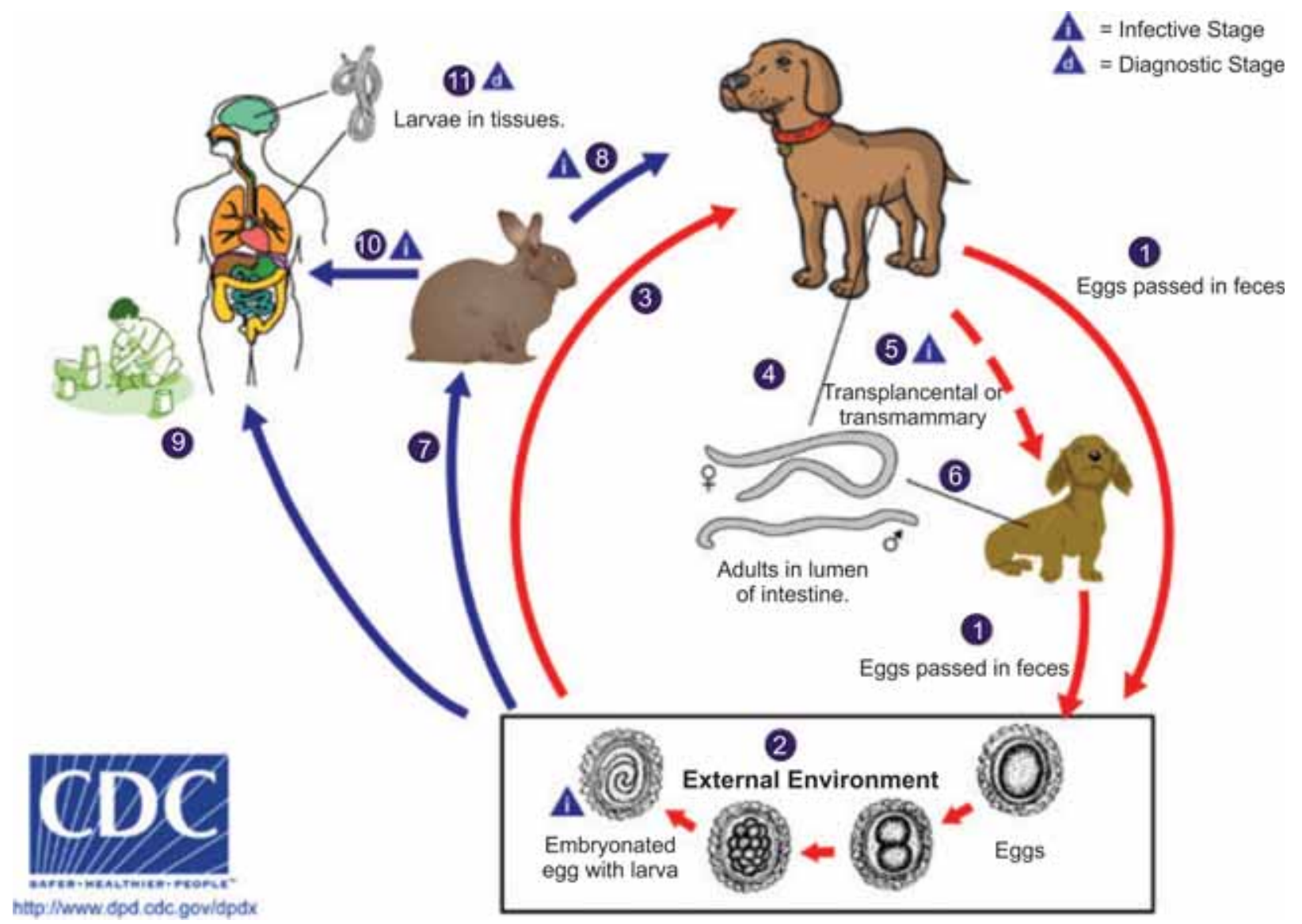

FIGURE 3. Life Cycle

Source: Centers for Disease Control and Prevention

volve lung (32-44\%), liver and spleen. Severe neurological infection and eye involvement are infrequent.

The diagnosis is confirmed by Elisa test $(\operatorname{IgM})$ (2).

Particularity of the case is represented by the atypical debut pneumonia like with very intensive thoracic pain and pulmonary infiltrate described by chest computer tomography, without fever or coughing, but with hypereosinophilia so tests for helminth infections were done.

Deep vein thrombosis and pulmonary embolism were diagnosed during the course of disease. Our question was: Could have been hypereosinophilia responsible for the patient thrombosis or was it only the trigger factor? As two genetic tests for trombophilia (MTHFR A1298C gene and PAI1 $675)$ were positive we considered thrombosis in the context of patient hipercoagulable status. Data from literature (4) describe the implication of
MTHFR A1298C gene and PAI1 675 in deep vein thrombosis.

\section{FOLLOWING UP THE PATIENT}

After the treatment with Albendazole pulmonary infiltrate disappeared and a decrease in number of eosinophilic cells and IgE was noticed.

In the present time the patient is under anticoagulant treatment with warfarin (he didn't tolerate apixaban because of increase of the liver enzymes). $\mathrm{He}$ is clinically normal. Blood tests are in normal range.

We continue to follow up the patient.

\section{CONCLUSIONS}

Toxocariasis infection induced hypereosinophilia which was trigger factor for deep vein thrombosis and pulmonary embolism in a patient of 53 years old diagnosed with procoagulant status. 


\section{REFERENCES}

1. Steven M. Holland; John I. Gallin. Disorders of Granulocytes and Monocytes; Eosinophilia pag. 481. Harrison's Principles of Internal Medicine $18^{\text {th }}$ Edition, 2012.

2. Mandell Bennet Dollin. Chapter 289 - Visceral Larva Migrans and Other Unusual Helminth Infections. Principles and Practice of Infectious Diseases $6^{\text {th }}$ Edition. Theodore E. Nash. Eosinophilia: Clinical Significance. Visceral Larva Migrans (Toxocariasis) -pag. 3294
3. Paul R.J. Ames, Giuseppina Aloj, Fabrizio Gentile. Hematology and Reumatology Department, Airedale General Hospital. Eosinophilia and Thrombosis in Parasitic Diseases: An Overview/ pag. 34; source PubMed

4. Milka Koupenowa, Beate E.Kehrel, HeatherA. Corkrey, Jane E. Freedman. Thromboses and Platelets: An Update. European Heart Journal 2017; 38(11);785-791 